\title{
Presentación Foreword
}

\author{
José María Sauca \\ Universidad Carlos III de Madrid \\ Dirección de la revista Eunomía
}

DOI: https://doi.org/10.20318/eunomia.2018.4338

Presentamos al lector la decimoquinta entrega de Eunomía. Revista en Cultura de la Legalidad. Nos complace reparar en que son ya siete los años en que anunciamos el comienzo del curso académico de la misma manera. Asimismo, valoramos positivamente que la estructura del número mantenga su carácter ordinario y creemos que los trabajos recogidos en el mismo representan aportaciones rigurosas y plurales en la línea editorial de la revista y refuerzan su carácter interdisciplinar.

La sección de Estudios se inicia con el trabajo del profesor de teoría política de la Universidad de la República, Javier Gallardo, en el que aborda una revisión de la idea de identidad ciudadana focalizando su análisis en la experiencia uruguaya. Alfonso Ruíz Miguel es el autor del segundo de los trabajos. El filósofo del Derecho de la Universidad Autónoma de Madrid presenta un estudio sobre el derecho de gracia, desarrollando el análisis de los que podrían ser los dos criterios básicos justificativos del mismo. La tercera aportación corresponde a Javier Álvarez. El estudio del penalista aporta una evaluación comparada y prospectiva sobre la incidencia de las propuestas de diversas oficinas de Naciones Unidas en materia de violencia de género y aborto en el futuro Código Penal de Honduras. Finalmente, Marina Gascón revisita una temática de largo aliento en su trayectoria: el carácter general de la objeción de conciencia y analiza los requisitos que debe cumplir su protección prima facie frente a un deber jurídico.

La sección de Foro y Ágora se abre con el trabajo de María Jimena Sáenz y Miguel Ángel Benedetti en el que analizan el impacto de la fórmula de las audiencias públicas en las decisiones de la Corte Suprema Argentina. En segundo lugar, con continuidad temática con el segundo trabajo de la sección anterior, Edgardo Rodríguez -recientemente nombrado Director de Políticas y Gestión en Derechos Humanos del Ministerio de Justicia y Derechos Humanos del Perú- analiza las peculiaridades de la concesión de un indulto a Fujimori en el país andino a finales del pasado año. La tercera, a cargo de la profesora Laura Nuño, estudia una cuestión que ha adquirido notas de actualidad, relativa a la regulación de la prostitución en el 
modelo alemán. Finalmente, Aurelio de Prada aborda el estudio de la cuestión del recurso de amparo constitucional en el contexto, que también ha devenido en boga, del control de la evaluación de la investigación de los profesores universitarios en España.

La sección de Voces ofrece diez nuevas entradas. La mitad de ellas presentan un carácter prevalentemente teórico y general. Sus enunciados son Solidaridad, Dignidad humana, Objeción de conciencia -también en continuidad temática con el trabajo de Marina Gascón arriba referido-, Protesta así como, Seguridad Internacional y su autoría respectiva corresponde a Roberto R. Aramayo, Jesús Ignacio Delgado, Rosana Triviño, Alicia García Ruiz y Thomas Gil. Las cuatro siguientes se centran en aspectos institucionales de la cultura de la legalidad: Cultura constitucional, Confianza en la Administración Pública, Códigos de buenas prácticas y Derecho a comprender la ley y que son obra, respectivamente, de Mariano C. Melero, Cecilia Güemes, Txetxu Ausín y Germán Jair Arenas Arias. La sección se cierra con la aportación de Alejandro Coteño denominada Terrorista individual.

El Releyendo a... recoge la aportación del profesor de filosofía Javier Peña Echevarría que introduce y traduce el IV Discurso de la Politique Naturelle de Holbach. En el contexto de la importante tarea de traducción de las obras de este autor que se está realizando actualmente en España, esta aportación nos anticipa uno de los discursos de esta obra de madurez y que resulta especialmente relevante de la visión del ilustrado sobre los criterios justificativos de la sociedad y de la propuesta institucional que la canalice. Según señala $M_{0}$ range ${ }^{1}$, parece que hubo dos traducciones parciales de este trabajo que datan de 1811 pero ambas estaban sujetas a las peculiares circunstancias ideológicas del momento. De esta forma, la aportación de Peña Echevarría representa una auténtica innovación en este contexto y su explicación, en línea con algunos de sus recientes trabajos, viene a cubrir un importante vacío en la comprensión del legado enciclopedista.

Finalmente, la sección del Rincón de lecturas mantiene su subdivisión interna en tres apartados. En el primero, el Debatiendo recoge las contribuciones de Nieves San Emeterio y Pablo Sánchez León en las que, respectivamente, comentan en trabajo que María José Fariñas publicó, con el título neoliberalismo vs democracia, en el anterior número de la revista. Cada una de las contribuciones nos ofrece una mirada discrepante, al menos parcialmente, con las tesis de la ponencia y lo hace, a su vez, discrepando entre sí.

\footnotetext{
${ }^{1}$ Claude Morange, «Sobre dos traducciones al castellano (en 1811) de La Politique Naturelle del Barón de Holbach» en Documentos de Trabajo de la Asociación Española de Historia Económica, DT-AEHE № 1515, 2015 [www.aehe.es/wp-content/uploads/2015/04/dt-aehe1515.pdf (Úl. Cons.: 5/09/2018)].
} 
El Book Fórum presenta una estructura peculiar y disfruta de una extensión muy superior a lo habitual en la subsección. Ordinariamente, en ella suelen intervenir un par de críticos que reciben la respuesta del autor y el debate viene a prolongarse en torno a unas veinticinco páginas que nunca han rebasado la treintena. En esta ocasión los críticos alcanzan el número de siete y el alargamiento del debate sobrepasa el centenar de páginas. La razón de esta excepcionalidad se encuentra en el carácter del libro escogido y, también, en la singularidad de su autor. Nombres propios: el libro en cuestión es Visión lógica del Derecho y su autor es Lorenzo Peña. El recientemente jubilado profesor de Investigación del Instituto de Filosofía del Consejo Superior de Investigaciones Científicas de Madrid amerita un largo reconocimiento por parte de esta revista, por parte de las perspectivas académicas de la cultura de la legalidad y, por demás, por parte de la filosofía jurídica en lengua española. Así, el profesor Peña tomó parte activa en los equipos de investigación que promovieron la creación de Eunomía a principios de esta década y ha permanecido vinculado a la misma durante todo este período. Su visión del Derecho está animada por un profundo racionalismo que, articulado con su apuesta por una lógica singular, le lleva a sostener peculiares tesis iusnaturalistas. Efectivamente, esta visión del Derecho resulta muy singular, me atrevería a señalar que excepcional, y coloca al profesor Peña en la posición permanente de ir contra corriente. Creo que ello tiende a explicar el gusto por la polémica que le anima. En estos años, hemos podido observarla en sus Escritos republicanos, en su minucioso e implacable análisis de la figura de Bobbio o en sus comentarios sobre la secesión de Cataluña o por abogar en favor de una sentencia absolutoria para los condenados en el caso de La Manada. En este marco el trabajo, Visión lógica del Derecho viene a constituir la más acabada síntesis de su larga trayectoria intelectual. El libro publicado el año pasado se basa en lo que fue su tesis doctoral en Derecho (la de filosofía fue leída en la Universidad de Lieja hace casi cuarenta años) y sintetiza un concepto de Derecho vinculado a la idea de bien común que se desarrolla recurriendo a un sistema de lógica gradualista o paraconsistente. Nuevamente, tesis minoritaria y ánimo polémico en su defensa. El guante ha sido recogido por siete filósofos del Derecho que sostienen tesis discrepantes entre sí, pero con los que las desavenencias no son radicales. Así, la controversia se desarrolla en un contexto teórico que, en sentido amplio, tiene continuidad y favorece que el debate adquiera una mayor precisión. Los intervinientes, siguiendo el orden con el que se formulan las contestaciones de Peña, son Julia Barragán, Manuel Atienza, Andrés Ollero, Mariano C. Melero, Alfonso García Figueroa, Marcelo Vásconez y José Juan Moreso. En definitiva, ojalá que esta pequeña contribución de la revista sea útil para el reconocimiento a un incansable trabajo intelectual, una vastísima cultura y un espíritu académico que ha defendido su juicio con toda la rectitud posible.

Cerramos la sección con las recensiones. En esta ocasión, César Cruz nos comenta el libro editado por Víctor Lapuente sobre La Calidad de las instituciones en España; Javier Zamora el de Manuel Arias sobre Antropoceno y Carlos Alonso sobre el libro de Ricardo Cueva titulado Estudios sobre la libertad en América. Por su parte, Marcelo Vásconez reseña con carácter general el libro objeto del Book fórum antes presentado. 
No quisiera terminar sin hacer mención al reconocimiento que deben recibir todos aquellos que, de un modo $u$ otro, han participado en la gestación de este número de la revista. Entre ellos, quisiera significar especialmente a los miembros salientes del consejo de edición de la misma: Candelaria Quispe, Julián Gaviria, Ana Catalina Arango, Jorge San Vicente y, especialmente, Edgardo Rodríguez por todo el silencioso trabajo realizado durante varios años. Asimismo, quisiera agradecer a Carlos Alonso toda su dedicación en el tiempo en que ha sido coordinador del citado consejo. Finalmente, quisiera dar la bienvenida a dicho órgano a Digno Montalván y Alejandro Coteño así como a Rubén García Higuera en su asunción de la coordinación del mismo.

En definitiva, entregamos al lector un nuevo número de Eunomía y conseguimos hacerlo en los plazos debidos y tras haber satisfecho los protocolos de calidad al uso en el funcionamiento de las revistas académicas. Ojalá que todo el trabajo merezca la pena a los ojos del lector. 